\title{
Normalization of hepatic glucose regulation despite systemic insulin delivery. Studies in patients with pancreatic transplantation for Type 1 (insulin-dependent) diabetes mellitus
}

\author{
H. Wilczek ${ }^{1}$, R. Gunnarsson ${ }^{2}$, P.Felig ${ }^{3}$, J. Östman $^{2}$, C.-G. Groth ${ }^{1}$ and J. Wahren ${ }^{3}$ \\ Departments of ${ }^{1}$ Transplantation Surgery, ${ }^{2}$ Medicine and ${ }^{3}$ Clinical Physiology, Huddinge Hospital, Karolinska Institute, Stockholm, \\ Sweden
}

\begin{abstract}
Summary. With current surgical techniques for pancreatic transplantation, the graft is anastomosed to the iliac vessels, resulting in delivery of insulin to the systemic circulation rather than to the portal vein as in healthy man. The possible influence of the altered route of insulin delivery on the regulation of splanchnic glucose metabolism was studied in four patients with Type 1 (insulin-dependent) diabetes mellitus at 6-19 months after combined pancreatic and kidney transplantation. Four non-diabetic, age-matched renal transplant recipients and two groups of age-matched healthy subjects served as controls. The studies were carried out in the basal state and during two rates of intravenous glucose infusion (2 and $\left.4 \mathrm{mg} \cdot \mathrm{kg}^{-1} \cdot \mathrm{min}^{-1}\right)$. Fasting arterial glucose and splanchnic glucose output was similar in all groups. Basal hyperinsulinaemia was present in pancreatic graft recipients compared to healthy subjects. During low rate intravenous
\end{abstract}

glucose infusion splanchnic glucose output decreased to a similar extent in all groups. With the higher glucose infusion rate $\left(4 \mathrm{mg} \cdot \mathrm{kg}^{-1} \cdot \mathrm{min}^{-1}\right)$ a net glucose uptake was observed which was similar in all three groups. Peripheral glucose uptake was unchanged at the lower glucose infusion rate but increased by $45-55 \%$ at the higher rate. It is concluded that despite systemic insulin delivery from a heterotopic pancreatic graft, hepatic glucose metabolism appears normal both in the post-absorptive state and in response to glucose-stimulated endogenous insulin secretion. Portal insulin delivery is thus not necessary for normal hepatic glucose metabolism in the Type 1 diabetic patient.

Key words: Type 1 (insulin-dependent) diabetes mellitus, pancreatic transplantation, hepatic glucose regulation.
The importance of the liver in blood glucose homeostasis has long been recognized. Previous studies have shown the liver to be the primary site of action of small increments in endogenous insulin [1-3]. Under normal circumstances the liver is exposed to concentrations of insulin in portal venous blood which are approximately twice those in the systemic circulation [4]. Small increments in arterial plasma insulin levels normally inhibit hepatic glucose output [1]. The greater response of the liver, compared to the periphery, to the minor changes in insulin concentrations may reflect a greater hepatic sensitivity to a given insulin concentration, or it may be a result of the higher ambient levels of endogenous insulin in portal venous compared to arterial blood. If the fine regulation of hepatic glucose metabolism is dependent on portal insulin delivery, this could have consequences for the choice of surgical technique in pancreatic transplantation. With current techniques the venous outflow from the pancreatic graft and thus the delivery of insulin, is to the systemic rather than the portal circulation [5]. That glucose metabolism in Type 1 (insulin-dependent) diabetes mellitus normalizes after pancreatic transplantation is evident from the normal blood glucose concentrations when exogenous insulin administration is discontinued $[6,7]$. A question that has not been addressed is whether heterotopic pancreatic transplantation alters the liver's contribution to glucose metabolism relative to that of peripheral tissues. In the present study, the hepatic venous catheter technique has been employed to determine splanchnic glucose regulation in four Type 1 diabetic patients following successful heterotopic pancreatic transplantation. Specifically, we determined whether an i.v. glucose infusion, known to inhibit hepatic glucose output without stimulating peripheral glucose uptake in normal subjects, has similar effects in patients with heterotopic pancreatic transplantation. A higher glucose infusion rate was also employed to evaluate the net splanchnic glucose uptake. 
Table 1. Clinical characteristics of the patients

\begin{tabular}{|c|c|c|c|c|c|c|c|c|c|}
\hline & $\begin{array}{l}\text { Age } \\
\text { (years) }\end{array}$ & $\begin{array}{l}\text { Body- } \\
\text { weight } \\
(\mathrm{kg})\end{array}$ & $\begin{array}{l}\text { Underlying } \\
\text { disease }\end{array}$ & $\begin{array}{l}\text { Duration } \\
\text { of diabetes } \\
\text { (years) }\end{array}$ & $\begin{array}{l}\text { Time from } \\
\text { transplant to } \\
\text { study(months) }\end{array}$ & $\begin{array}{l}\text { Fasting } \\
\text { blood glucose } \\
(\mathrm{mmol} / \mathrm{l})\end{array}$ & $\begin{array}{l}\text { IVGTT } \\
\text { k-value } \\
\% / \text { min }\end{array}$ & $\begin{array}{l}\mathrm{HbA}_{1} \\
\%\end{array}$ & $\begin{array}{l}\text { Serum- } \\
\text { creatinine } \\
\mu \mathrm{mol} / 1\end{array}$ \\
\hline \multicolumn{10}{|c|}{ Pancreatic graft recipients } \\
\hline 1 & 25 & 67.0 & Diabetes & 19 & 19 & 4.0 & 1.0 & 7.6 & 215 \\
\hline 2 & 40 & 66.5 & Diabetes & 24 & 14 & 3.3 & 0.9 & 6.5 & 124 \\
\hline 3 & 46 & 79.3 & Diabetes & 29 & 15 & 4.1 & 1.2 & 6.5 & 148 \\
\hline 4 & 33 & 67.0 & Diabetes & 28 & 6 & 3.9 & 1.0 & 6.7 & 256 \\
\hline 1 & 25 & 64.0 & $\begin{array}{l}\text { Pyelonephritis } \\
\text { chronica }\end{array}$ & - & 33 & 4.3 & 2.2 & 4.7 & 234 \\
\hline 2 & 23 & 55.0 & $\begin{array}{l}\text { Glomerulonephri- } \\
\text { tis chronica }\end{array}$ & - & 59 & 3.5 & 1.8 & 3.9 & 126 \\
\hline 3 & 42 & 87.5 & Nephrocalcinosis & - & 17 & 4.2 & 1.4 & 8.0 & 137 \\
\hline 4 & 30 & 79.0 & IgA-nephritis & - & 10 & 3.9 & - & 4.7 & 171 \\
\hline
\end{tabular}

Normal range: fasting blood glucose $3.1-5.6 \mathrm{mmol} / \mathrm{l}$, $\mathrm{k}$-value $>1.0 \% / \mathrm{min}, \mathrm{HbA}_{1}<8.5 \%$, serum creatinine $0-115 \mu \mathrm{mol} / \mathrm{l}$. IVGTT $=$ intravenous glucose tolerance test

\section{Subjects and methods}

\section{Subjects}

Four male patients, who had undergone successful combined renal and pancreatic transplantation, were examined. Characteristics of the graft recipients and measurements of graft function at the time of hepatic vein catheterization are given in Table 1.

Immunosuppressive therapy consisted of prednisolone $10 \mathrm{mg}$ daily in combination with either cyclosporine A 3 to $5 \mathrm{mg} / \mathrm{kg}$ daily or, in one patient, azathioprine. The purpose, nature and potential risks of the study were carefully explained to all subjects and informed consent was obtained before their participation. The study protocol was reviewed and approved by the ethics committee of our institution.

Four non-diabetic, age-matched renal transplant recipients were used as control subjects. Patient data for the control subjects are also presented in Table 1. Immunosuppression was achieved with cyclosporine A 4.8 to $5.9 \mathrm{mg} / \mathrm{kg}$ daily and prednisolone $10 \mathrm{mg}$ daily. The two transplant groups were matched for renal function and immunosuppression. Furthermore, another two groups of age-matched healthy subjects (seven in each group) also served as control subjects. One of these groups was used for comparison of basal data and the other for comparison during glucose infusion. All the healthy subjects had a normal body weight, normal fasting blood glucose and normal i.v. glucose tolerance tests. Results in the healthy subjects have been described previously $[8,9]$.

\section{Surgical technique in transplantation}

Heterotopic segmental pancreatic transplantation was performed [10]. The grafts were taken from cadaveric donors. The pancreatic graft (body and tail) was placed in the left iliac fossa and anastomosed to a jejunal Roux-en-Y loop for exocrine diversion. The vascular anastomosis was accomplished by connecting the splenic artery and vein to the iliac vessels. Insulin was thus secreted into the systemic venous system instead of to the portal vein. In conjunction with the pancreatic transplantation a renal transplantation was performed and the renal graft - obtained from the same donor - was anastomosed to the right iliac vessels.

\section{Study protocol}

In the pancreatic graft recipients the investigations were performed 6-29 months after transplantation and in the non-diabetic renal graft recipients $10-59$ months post transplantation. The studies were performed on the morning after a $12 \mathrm{~h}$ overnight fast. Teflon catheters were inserted percutaneously into a brachial artery and an antecubital vein. A no. 8 Cournand catheter was then inserted percutaneously into an antecubital or femoral vein and advanced under fluoroscopic control to a right-sided hepatic vein. The tip of the catheter was placed 3 to $4 \mathrm{~cm}$ from the wedge position and its location was checked repeatedly by fluoroscopy during the study. Only local anaesthesia was used. Patency of the catheters was maintained throughout the study by flushing with isotonic $154 \mathrm{mmol} / \mathrm{l} \mathrm{NaCl}$ intermittently, heparin was not used. The peripheral venous catheter was used for the infusion of indocyanine green (for estimation of hepatic blood flow [11,12]), and for glucose infusion. The arterial and hepatic venous catheters were used for simultaneous blood sampling. The splanchnic exchange of glucose and glucogenic precursors was calculated as the arterialhepatic venous concentration difference multiplied by the estimated hepatic blood flow. After a basal state of $45 \mathrm{~min}$, glucose was infused i. v. as a $20 \%$ solution at a rate of $2 \mathrm{mg} \cdot \mathrm{kg}^{-1} \cdot \min ^{-1}$ for $45 \mathrm{~min}$. This has previously been demonstrated in normal subjects to cause a prompt reduction in splanchnic glucose release without influencing peripheral glucose utilization [1]. All transplant recipients were also given a glucose infusion at a rate of $4 \mathrm{mg} \cdot \mathrm{kg}^{-1} \cdot \mathrm{min}^{-1}$ for a further $45 \mathrm{~min}$. Blood samples were obtained from the arterial and hepatic venous cathetersin the basal state, at the start of glucose infusion, and then at 10 , 20,30 and $45 \mathrm{~min}$.

\section{Estimation of peripheral glucose utilization}

In the basal state the rate of total peripheral glucose utilization equals the rate of hepatic glucose production. Since arterial glucose levels were stable during the last $15 \mathrm{~min}$ of the glucose infusion at a rate of $2 \mathrm{mg} \cdot \mathrm{kg}^{-1} \cdot \mathrm{min}^{-1}$, glucose utilization was estimated as the sum of exogenously infused glucose and the residual splanchnic glucose output [1].

\section{Chemical analyses}

The methods employed for measurements of glucose, lactate, pyruvate, glycerol and amino acids have been described previously [1,2, $13,14]$. Non-esterified fatty acids were determined by the gas chromatographic procedure of Hagenfeldt [15]. Insulin was determined by radioimmunoassay according to Heding [16].

\section{Statistical analysis}

Standard statistical methods have been employed, using analysis of variance or the unpaired $t$-test when applicable. Data in the text, tables and figures are given as mean \pm SEM. 
Table 2. Arterial concentrations of substrates and hormones in the basal state

\begin{tabular}{|c|c|c|c|c|c|}
\hline & Pancreatic graft recipients & $\begin{array}{l}\text { Non-diabetic renal } \\
\text { graft recipients }\end{array}$ & $\begin{array}{l}p \text {-value } \\
\text { Pvs R }\end{array}$ & Healthy subjects & $\begin{array}{l}p \text {-value } \\
\text { PvsHS }\end{array}$ \\
\hline Glucose, $\mathrm{mmol} / \mathrm{l}$ & $3.84 \pm 0.17$ & $3.98 \pm 0.17$ & NS & $4.42 \pm 0.19$ & NS \\
\hline Lactate, $\mathrm{mmol} / \mathrm{l}$ & $0.47 \pm 0.04$ & $0.49 \pm 0.04$ & NS & $0.60 \pm 0.06$ & NS \\
\hline Glycerol, $\mu \mathrm{mol} / 1$ & $84 \pm 12$ & $61 \pm 11$ & NS & $52 \pm 4$ & $<0.02$ \\
\hline Beta-OH-butyrate, $\mu \mathrm{mol} / 1$ & $182 \pm 70$ & $120 \pm 46$ & NS & $185 \pm 52$ & NS \\
\hline Acetoacetate, $\mu \mathrm{mol} / \mathrm{l}$ & $113 \pm 33$ & $75 \pm 25$ & NS & $78 \pm 19$ & NS \\
\hline Alanine, $\mu \mathrm{mol} / 1$ & $244 \quad \pm 24$ & $201 \pm 12$ & NS & $240 \pm 27$ & NS \\
\hline
\end{tabular}

Data represent the mean of two to three measurements in each subject in both groups. $\mathrm{P}=$ pancreatic graft recipients, $\mathrm{R}=$ non-diabetic renal graft recipients, $\mathrm{HS}=$ healthy subjects

\section{Results}

Arterial concentrations. The mean arterial substrate and hormone concentrations in the basal state for the pancreatic graft recipients, the renal graft recipients and healthy subjects are shown in Table 2. Fasting arterial blood glucose was slightly lower in pancreatic graft recipients than in the other two groups, but did not differ significantly. The glycerol levels were significantly higher in the pancreatic graft recipients than in the healthy subjects, while no significant difference was found between the former and non-diabetic renal graft recipients. The non-esterified fatty acid levels tended to be higher in the pancreatic graft recipients than in the other two groups. There was no difference in the arterial concentration of lactate, pyruvate, B-hydroxybutyrate, acetoacetate or amino acids between any of the groups. Arterial insulin levels did not differ significantly between pancreatic graft recipients and nondiabetic renal graft recipients, but were significantly higher $(p<0.02)$ in the pancreatic graft recipients than in healthy subjects.

\section{Splanchnic glucose metabolism}

The basal splanchnic glucose output was almost identical in pancreatic graft recipients and non-diabetic renal graft recipients and did not differ significantly from healthy subjects (pancreatic graft recipients $0.86 \pm 0.31 \mathrm{mmol} /$ min, non-diabetic renal graft recipients $0.85 \pm$ $0.14 \mathrm{mmol} / \mathrm{min}$, healthy subjects $0.79 \pm 0.13 \mathrm{mmol} / \mathrm{min}$ ). The proportion of glucose output which could be accounted for by gluconeogenesis was estimated from the splanchnic precursor uptake. Among the pancreatic graft recipients the total uptake of gluconeogenic precursors could account for $32 \%$ of the splanchnic glucose output. For non-diabetic renal transplant recipients and healthy subjects the figure was $26 \%$ and $29 \%$, respectively (Fig. 1).

\section{Response to glucose infusion}

Glucose infusion elicited a parallel rise in arterial glucose concentration in the three groups. Arterial insulin concentration also rose in a similar fashion in pancreatic graft re- cipients, non-diabetic renal graft recipients and healthy subjects, and the magnitude of the increment was much the same in all groups. As in the basal state, during glucose infusion the pancreatic graft recipients showed a significant arterial hyperinsulinaemia compared to healthy subjects $(p<0.006)$ (Fig.2). They also tended to have higher arterial insulin levels than the non-diabetic renal graft recipients at 45 and $90 \min (p<0.06)$.

Net splanchnic glucose output decreased in a similar manner in all three groups: pancreatic graft recipients $-0.77 \pm 0.25 \mathrm{mmol} / \mathrm{min}(-90 \%)$, non-diabetic renal graft recipients $-0.79 \pm 0.12 \mathrm{mmol} / \mathrm{min}(-93 \%)$, healthy subjects $-0.81 \pm 0.18 \mathrm{mmol} / \mathrm{min}(-70 \%)$ (Fig. 2). All

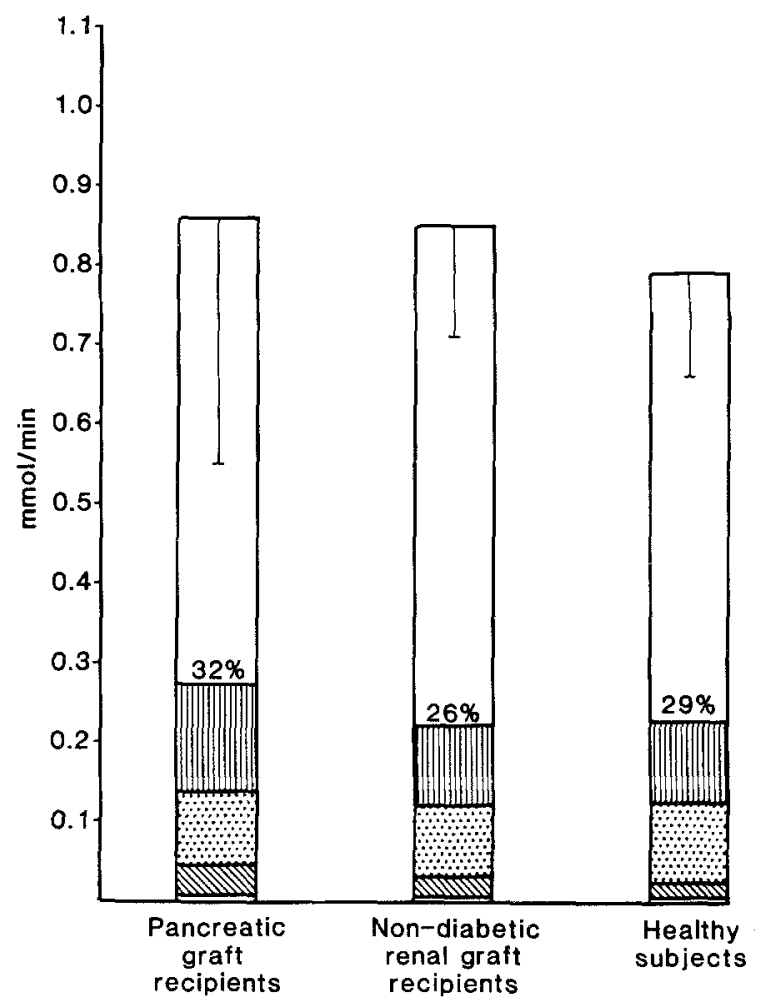

Fig. 1. Splanchnic glucose output and uptake of glucogenic substrates in the basal state for pancreatic graft recipients, non-diabetic renal graft recipients and healthy subjects. The numbers indicate the proportion of total splanchnic glucose output that can be accounted for by uptake of glucose precursors. Mean \pm SEM are indicated. InI Lactate, Amino acids, Glycerol, $\square$ Pyruvate 

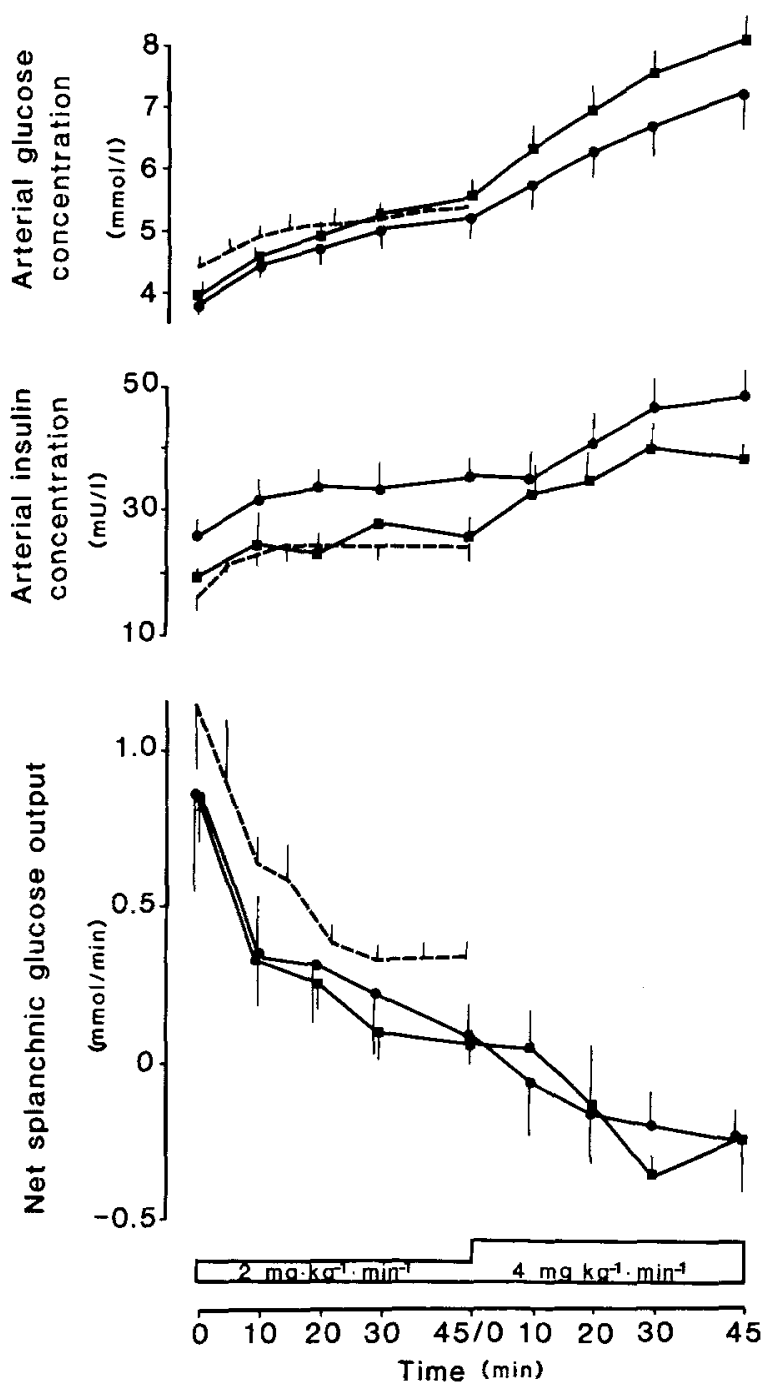

Fig. 2. Average arterial glucose levels, arterial insulin concentrations and net splanchnic glucose exchange in the basal state and during infusion of glucose at 2 and $4 \mathrm{mg} \cdot \mathrm{kg}^{-1} \cdot \mathrm{min}^{-1}$, respectively, in pancreatic graft recipients $(\bullet)$, non-diabetic renal graft recipients $(\square-\square)$ and healthy subjects (---). Mean \pm SEM are indicated

Table 3. Influence of glucose infusion on estimated peripheral glucose utilization $^{\text {a }}$ (mean \pm SEM)

\begin{tabular}{lll}
\hline & \multicolumn{2}{l}{$\begin{array}{l}\text { Estimated peripheral glucose } \\
\text { utilization (mmol/min) }\end{array}$} \\
\cline { 2 - 3 } & Basal $^{\mathrm{b}}$ & $\begin{array}{l}\text { Glucose infusion } \\
2 \mathrm{mg} \cdot \mathrm{kg}^{-1} \cdot \mathrm{min}^{-1}\end{array}$ \\
\hline $\begin{array}{l}\text { Pancreatic graft recipients } \\
\text { Non-diabetic renal graft }\end{array}$ & $0.86 \pm 0.31$ & $0.92 \pm 0.12$ \\
recipients & $0.85 \pm 0.14$ & $0.87 \pm 0.12$ \\
Healthy subjects & $1.15 \pm 0.21$ & $1.14 \pm 0.07$ \\
\hline
\end{tabular}

${ }^{a}$ Estimated peripheral glucose utilization $=$ splanchnic glucose production + glucose infused.

${ }^{b}$ In the basal state peripheral glucose utilization is equal to splanchnic glucose production

three groups showed a similar estimated peripheral glucose uptake in the basal state (Table 3 ). The uptake did not change during the low dose $\left(2 \mathrm{mg} \cdot \mathrm{kg}^{-1} \cdot \mathrm{min}^{-1}\right)$ exogenous glucose infusion in any of the groups (Table 3 ). When the glucose infusion rate was stepped up ( $4 \mathrm{mg}$. $\left.\mathrm{kg}^{-1} \cdot \mathrm{min}^{-1}\right)$ a similar increase in the peripheral glucose uptake was seen in the two transplant groups (Table 3).

\section{Discussion}

In the present study the hepatic venous catheter technique has been employed to examine how heterotopic pancreatic transplantation in man affects hepatic glucose regulation and precursor uptake in the basal state and after stimulation of endogenous insulin secretion by infusion of glucose. Successful transplantation of vascularized pancreatic grafts has been shown to restore the patient's plasma glucose to normal values $[6,7]$. The four pancreatic graft recipients examined in this study had all achieved a normal glucose homeostasis in spite of systemic rather than portal delivery of endogenous insulin. There was a moderate hyperinsulinaemia among the pancreatic graft recipients, arterial insulin levels being approximately $50 \%$ higher than in the other two groups. In the non-diabetic renal graft recipients the insulin levels were similar to those in the healthy subjects. The peripheral hyperinsulinaemia was expected and most probably caused by the systemic delivery of the endocrine secretion from the pancreatic graft. This is also supported by the observed hyperinsulinaemia following heterotopic pancreatic transplantation in animals $[17,18]$. No significant difference was observed between pancreatic graft recipients and the control subjects regarding basal net splanchnic glucose output. In addition, the total splanchnic uptake of gluconeogenic precursors could account for a similar proportion of the glucose output in the pancreatic graft recipients and the control subjects. Thus, there was no significant difference between pancreatic graft recipients, non-diabetic renal graft recipients and the healthy subjects in the basal state with regard to total splanchnic glucose output or estimated hepatic gluconeogenesis. These observations indicate that the hepatic glucogenic processes in the basal state proceeded in an apparently normal manner in the pancreatic graft recipients despite ongoing systemic insulin delivery and modest peripheral hyperinsulinaemia. However, since plasma glucagon and C-peptide were not measured, it is difficult to draw firm conclusions regarding hepatic insulin sensitivity of the subjects examined in the present studies. Of particular interest was the effect of the glucose infusion on splanchnic glucose output and peripheral glucose utilization. Previous studies in normal subjects have shown that infusion of glucose at a rate of $2 \mathrm{mg} \cdot \mathrm{kg}^{-1} \cdot \mathrm{min}^{-1}$, causing an $8-10 \mu \mathrm{U} / \mathrm{ml}$ increase in peripheral insulin levels, results in a $80 \%$ inhibition of splanchnic glucose output but fails to stimulate peripheral glucose utilization [1]. Virtually identical responses in splanchnic and peripheral glucose balances were observed in the pancreatic graft recipients in the present study. Both the absolute and the relative declines in splanchnic glucose output were identical in the three groups studied. Moreover, a glucose infusion rate of $2 \mathrm{mg} \cdot \mathrm{kg}^{-1} \cdot \mathrm{min}^{-1}$ gave no stimulation of peripheral glucose utilization in the pancreatic graft recipients despite the systemic delivery of insulin and the higher peripheral insulin concentration in this group. The greater sensitivity 
of hepatic compared to peripheral tissues to small increments in insulin secretion is thus not dependent on the portal delivery of insulin. Moreover, when insulin levels were further increased by stepping up the glucose infusion rate to $4 \mathrm{mg} \cdot \mathrm{kg}^{-1} \cdot \mathrm{min}^{-1}$, the net uptake of glucose observed in the pancreatic graft recipients was comparable to that in the renal graft recipients, in whom portal insulin delivery is maintained.

In the present study insulin was measured as total insulin concentrations rather than free insulin levels. However, the pancreatic transplant patients had not received exogenous insulin for 6 months or longer (Table 1) prior to the study. The half-life for insulin antibodies in these patients is of the order of 10-11 days [19,20]. Consequently, it is quite likely that the measurements of insulin were free of interference from insulin antibodies and that the observed values adequately reflect free insulin concentrations.

The surgical techniques most often employed in pancreatic transplantation consist of leading the graft's venous outflow and thus its insulin secretion into the systemic instead of the portal circulation. In view of the present findings, we conclude that in spite of the non-physiological systemic insulin delivery and consequent hyperinsulinaemia following heterotopic pancreatic transplantation, normal hepatic glucose regulation is achieved. Thus, it does not seem necessary to drain the venous outflow of the pancreatic graft into the portal venous system in order to attain normal glucose regulation in the diabetic patient. It also seems reasonable to assume that other therapeutic modalities in the diabetic patient using continuous systemic insulin administration, should be capable of creating normal glucose homeostasis.

Acknowledgements. This work was supported by grants from the Swedish Medical Research Council (no.3108), the Swedish Diabetes Association, the Karolinska Institute and the Oskar and Edla Johansson Foundation.

\section{References}

1. Felig P, Wahren J (1971) Influence of endogenous insulin secretion on splanchnic glucose and amino acid metabolism in man. $J$ Clin Invest 50: 1702-1711

2. Wahren J, Felig P, Cerasi E, Luft R (1972) Splanchnic and peripheral glucose and amino acid metabolism in diabetes mellitus. $\mathrm{J}$ Clin Invest 51: 1870-1878

3. Wahren J, Felig P, Cerasi E, Luft R, Hendler R (1973) Splanchnic glucose production and its regulation in healthy monozygote twins of diabetics. Clin Sci (Oxford) 44: 493-503

4. Blackard WG, Nelson NC (1970) Portal and peripheral vein immunoreactive insulin concentrations before and after glucose infusion. Diabetes 19:302-306

5. Sutherland DER (1981) Pancreas and islet transplantation. II. Clinical Trials. Diabetologia 20: 433-450
6. Tydén G, Lundgren G, Wilczek H, Klintmalm G, Öst L, Gunnarsson R, Östman J, Groth CG (1984) Recent experience with pancreatic transplantation at Huddinge Hospital. Transplant Proc 16: 1270-1273

7. Groth CG, Tydén G, Lundgren G, Wilczek H, Klintmalm G, Öst L, Gunnarsson R, Östman J (1984) Segmental pancreatic transplantation with enteric exocrine diversion. World J Surg pp:257261

8. Wahren J, Felig P, Hagenfeldt L (1976) Effect of protein ingestion on splanchnic and leg metabolism in normal man and in patients with diabetes mellitus. J Clin Invest 57: 987-999

9. Cerasi E, Wahren J, Luft R, Felig P, Hendler R (1973) The regulation of splanchnic glucose production in subjects with low insulin response - a compensatory mechanism in prediabetes? Europe J Clin Invest 3: 193-200

10. Groth C-G, Collste H, Lundgren G, Wilczek H, Klintmalm G, Ringdén O, Gunnarsson R, Östman J (1982) Successful outcome of segmental human pancreatic transplantation with enteric diversion after modifications in technique. Lancet II: 522-524

11. Bradley SE (1948) Measurement of hepatic blood flow. Methods Med Res 1: 199-204, VIII

12. Caesar J, Shaldon S, Chiandussi L, Guevara L, Sherlock S (1961) The use of indocyanine green in the measurement of hepatic blood flow as a test of hepatic function. Clin Sci (London) 21:4357

13. Felig P, Wahren J (1971) Amino acid metabolism in exercising man. J Clin Invest 50:2703-2714

14. Wahren J, Felig P, Ahlborg G, Jorfeldt L (1971) Glucose metabolism during leg exercise in man. J Clin Invest 50: 2715-2725

15. Hagenfeldt L (1966) A gas chromatographic method for the determination of individual free fatty acids in plasma. Clin Chim Acta 13: 266-268

16. Heding LG, Faber O, Kasperska-Czyzykowa T, Sestoft L, Turner R (1979) Radioimmunoassay of proinsulin and hyperproinsulinemic states. In: Baba S, Kaneko T, Yanihara N (eds). Proinsulin, insulin, C-peptide. Excerpta Medica, Oxford-Amsterdam, pp 254 261

17. Bewick M, Mundy AR, Eaton B, Watson F (1981) The endocrine function of the heterotopic pancreatic allotransplant in dogs. III. The cause of hyperinsulinemia. Transplantation 31:23-25

18. Ruiz JO, Uchida H, Schultz LS, Lillehei RC (1972) Function studies after auto- and allotransplantation and denervation of pancreaticoduodenal segments in dogs. Am J Surg 123: 236-242

19. Östman J, Arner P, Groth C-G, Gunnarsson R, Heding L, Lundgren $G$ (1980) Plasma C-peptide and serum insulin antibodies in diabetic patients receiving pancreatic transplants. Diabetologia 19: $25-30$

20. Gunnarsson R, Bottazzo GF, Heding LG, Lernmark $\AA$, Groth C-G (1980) Islet cell, islet cell surface and insulin antibodies in two pancreatic allotransplant recipients. In: Autoimmune aspects of endocrine disorders. Proceedings of the Serono Symposia, 33: 299-303

Received: 21 December 1990

Dr. J.Wahren

Department of Clinical Physiology

Karolinska Hospital

Box 60500

S-10401 Stockholm

Sweden 